\title{
Construction of bis-, tris- and tetrahydrazones by addition of azoalkenes to amines and ammonia
}

\author{
Artem N. Semakin ${ }^{* 1,2}$, Aleksandr O. Kokuev², Yulia V. Nelyubina ${ }^{3}$, \\ Alexey Yu. Sukhorukov ${ }^{1}$, Petr A. Zhmurov ${ }^{1}$, Sema L. Ioffe ${ }^{1,2}$ \\ and Vladimir A. Tartakovsky ${ }^{1}$
}

\section{Full Research Paper}

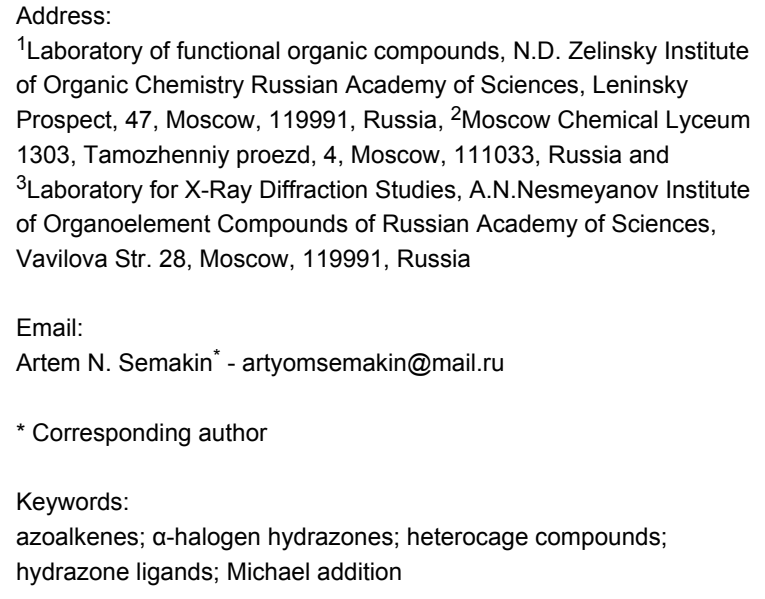

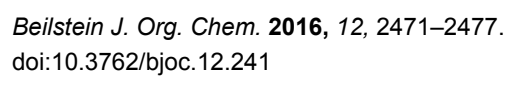

Received: 12 September 2016

Accepted: 03 November 2016

Published: 21 November 2016

Associate Editor: J. P. Wolfe

(C) 2016 Semakin et al.; licensee Beilstein-Institut. License and terms: see end of document.

\begin{abstract}
Exhaustive Michael-type alkylations of amines and ammonia with azoalkenes (generated from $\alpha$-halohydrazones) were demonstrated as an efficient approach to poly(hydrazonomethyl)amines - a novel class of polynitrogen ligands. An intramolecular cyclotrimerization of $\mathrm{C}=\mathrm{N}$ bonds in tris(hydrazonomethyl)amine to the respective 1,4,6,10-tetraazaadamantane derivative was demonstrated.
\end{abstract}

\section{Introduction}

Hydrazones are extensively used as key structural units in the design of various functional molecular and supramolecular architectures [1-17]. The hydrazone group is a chemically stable, easily assembled motif with prospective coordination properties, which can be tuned by substitution at the carbon and nitrogen atoms. Furthermore, a reversible $E / Z$-isomerism of the $\mathrm{C}=\mathrm{N}$ bond allows controllable modulation of the molecular geometry, for example through coordination with metal cations, hydrogen bond formation or irradiation. These unique struc-

tural features of the hydrazone fragment have been successfully exploited in the design of various molecular switches, fluorophores and machines.

Bis- and polyhydrazones exhibit a rich coordination chemistry owing to a variety of binding modes and are widely employed as ligands in metal-organic assemblies, sensors and catalytic systems [1-17]. More complex structures containing several hydrazone groups integrated with functional fragments upon 
coordination with metals can undergo significant changes in molecular shape and aggregation state that can be used in the design of smart adaptive materials [1,2]. Some important bisand trishydrazone ligands used in catalysis, coordination and supramolecular chemistry are shown in Figure 1.

Despite complex and sophisticated polyhydrazone ligands have been designed in the last decade, more structurally simple poly(hydrazonomethyl)amines of type I (Scheme 1), which are analogs of well-known poly(oximinomethyl)amine and poly(azolylmethyl)amine ligands [18-34], have not been prepared so far. In the present work, we focused on the development of a general approach to tertiary amines and polyamines bearing several hydrazonomethyl arms at the nitrogen atom(s). To achieve this goal, we suggested a straightforward methodology based on multiple Michael-type additions of azoalkenes A (generated from $\alpha$-halogen azacarbonyl precursor 1 [35-39]) to amines or ammonia (Scheme 1).

Though the chemistry and synthetic potential azoalkenes A have been a subject of considerable interest in the recent years $[38,39]$, their reactivity with amines is poorly explored. It has been demonstrated that amines react with azoalkenes $\mathbf{A}$ forming $\alpha$-aminohydrazones (Scheme 1) [35-49], however, addition of several azoalkene molecules to amines is virtually unknown. To

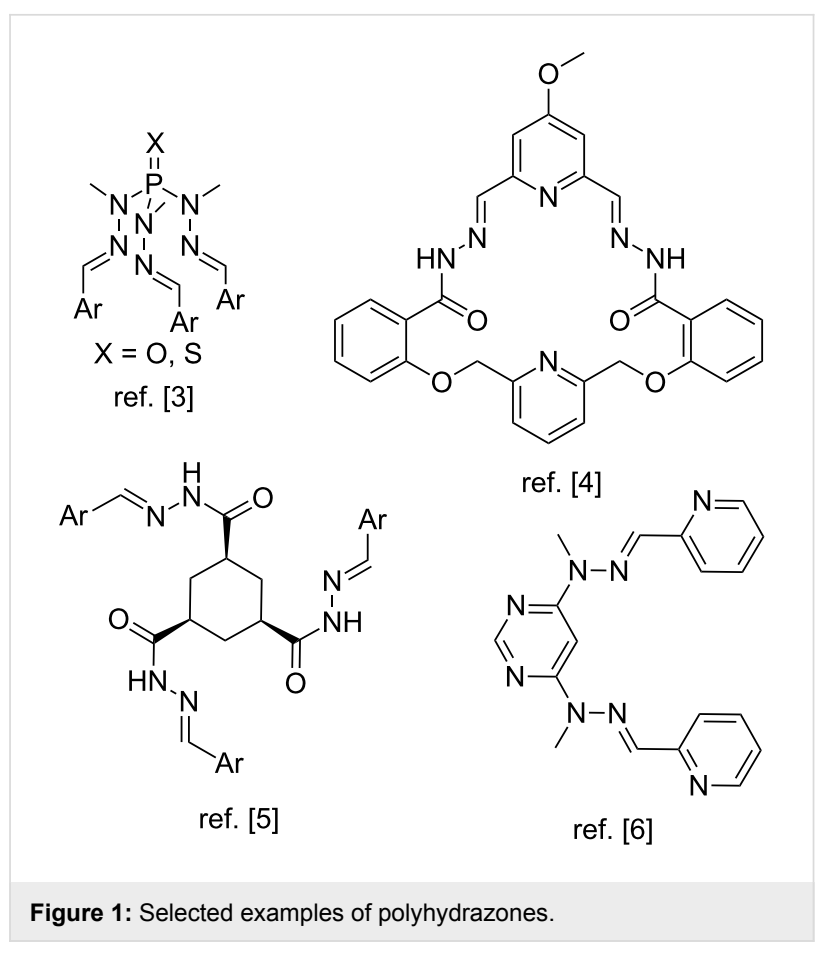

our knowledge, there is only one report on the formation of bishydrazones as undesirable products in reactions of some primary amines with $N$-tosylhydrazone of $o$-bromophenacyl bro-

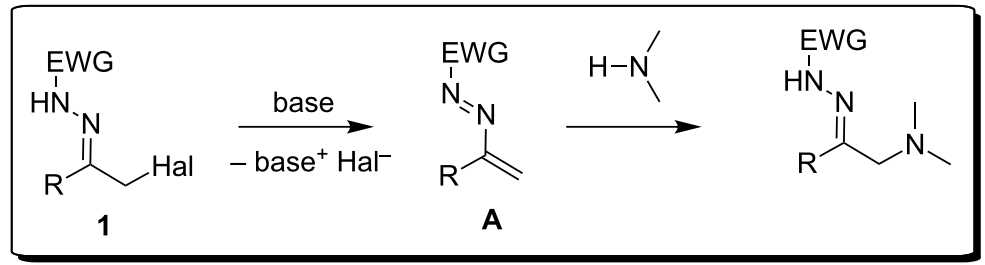

$\mathrm{R}^{\prime}-\mathrm{NH}_{2}$

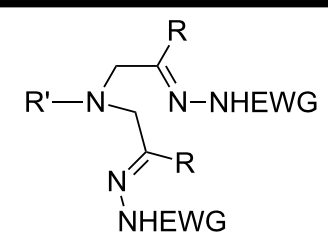

$\mathrm{NH}_{3}$

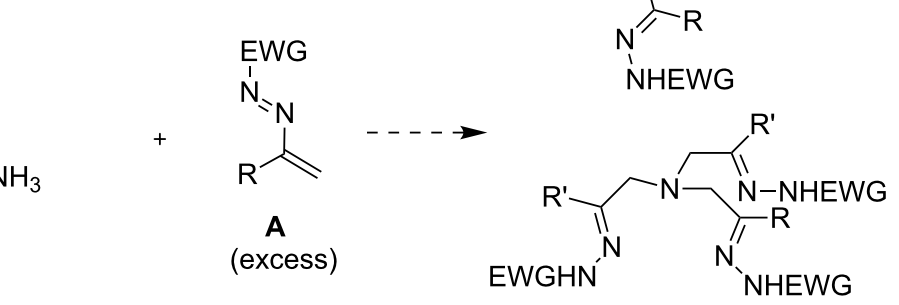

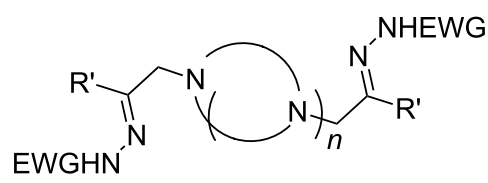

polyhydrazone ligands I 
mide [50]. We suppose that extension of the scope of azoalkene-amine coupling to ammonia, primary amines and polyamines would open an easy access to various polyhydrazones of type I. Therefore, a comprehensive study on the interaction of various amines with $\alpha$-halogen-substituted hydrazones 1 with amines and ammonia was undertaken.

\section{Results and Discussion Synthesis of $\alpha$-halogen-substituted hydra- zones 1}

Initially, $\alpha$-halogen-substituted hydrazones $\mathbf{1}$ were prepared from the corresponding carbonyl compounds and acylhydrazines or carbazates to study the reaction with amines (Scheme 2, for details see Supporting Information File 1). Acetic acid was added as catalyst and for suppression of the side reaction of the formed $\alpha$-halogen hydrazones with starting hydrazide [51]. The presence of acetic acid and mild reaction conditions $\left(0^{\circ} \mathrm{C}\right)$ was essential for the synthesis of hydrazones 1c and $1 \mathrm{~d}\left(\mathrm{R}^{1}=\mathrm{CH}_{3}, \mathrm{R}^{2}=\mathrm{CH}_{3}\right.$ or $\left.\left(\mathrm{CH}_{2}\right)_{6} \mathrm{CH}_{3}\right)$, probably because of the their enhanced $\mathrm{NH}$-acidity.

$$
\begin{aligned}
\text { 1-3 equiv } & \text { 1 equiv } \\
\mathrm{R}^{1} & =\mathrm{H}, \mathrm{CH}_{3}, \mathrm{Ph}, \mathrm{CO}_{2} \mathrm{Et} \\
\mathrm{R}^{2} & =\mathrm{Ot}-\mathrm{Bu}, \mathrm{OEt}, \mathrm{CH}_{3},\left(\mathrm{CH}_{2}\right)_{6} \mathrm{CH}_{3}, \mathrm{Ph}
\end{aligned}
$$

Scheme 2: Synthesis of a-halogen-substituted hydrazones 1 from a-halocarbonyl compounds and acylhydrazines or carbazates.

\section{Reaction of $\alpha$-halogen hydrazones 1 with benzylamine}

In our initial studies, benzylamine was chosen as model amine in reactions with $\alpha$-halogen-substituted hydrazones 1 . After brief optimization of the reaction conditions (solvent, base and ratio of reagents), it was found that alkylation of benzylamine with 2.0 equiv of Boc-hydrazone 1a and 2.0 equiv of potassium carbonate as a base in $\mathrm{MeOH}$ led to bishydrazone 2a in highest yield. The bright yellow color appeared in course of reagents mixing indicating the formation of azoalkene intermediate $\mathbf{A}$ [35-39]. Under these conditions, a range of other $\alpha$-halogen hydrazones $\mathbf{1 b}-\mathbf{d}, \mathbf{f}, \mathbf{g}$ were successfully converted to corresponding bishydrazones $\mathbf{2 b}-\mathbf{d}, \mathbf{f}, \mathbf{g}$ in good to high yields (Table 1). In case of $\mathbf{1 e}$, bearing a benzoyl group, the formation of a complex mixture was observed and target product $2 \mathbf{e}$ was not isolable (Table 1, entry 5).

\section{Variation of the amine component in the reaction with chloroacetone hydrazone $\mathbf{1 a}$}

The suggested reaction conditions were successfully extended to a range of primary and secondary amines providing corresponding polyhydrazones 3-9 (Figure 2).

Thus, propargylamine and (L)-valine methyl ester (generated in situ from the corresponding hydrochloride and an additional equivalent of potassium carbonate) in the reaction with two equivalents of chloroacetone hydrazone 1a provided the corresponding functionalized bishydrazones $\mathbf{3}$ and $\mathbf{4}$ in good yields (method A in Figure 2). On the other hand, an aromatic amine (aniline) under the aforementioned conditions led to monohydrazone $\mathbf{5}$ as a major product. Even when a 3-fold excess of $\mathbf{1 a}$

Table 1: Reaction of $\alpha$-halogen-substituted hydrazones 1 with benzylamine.

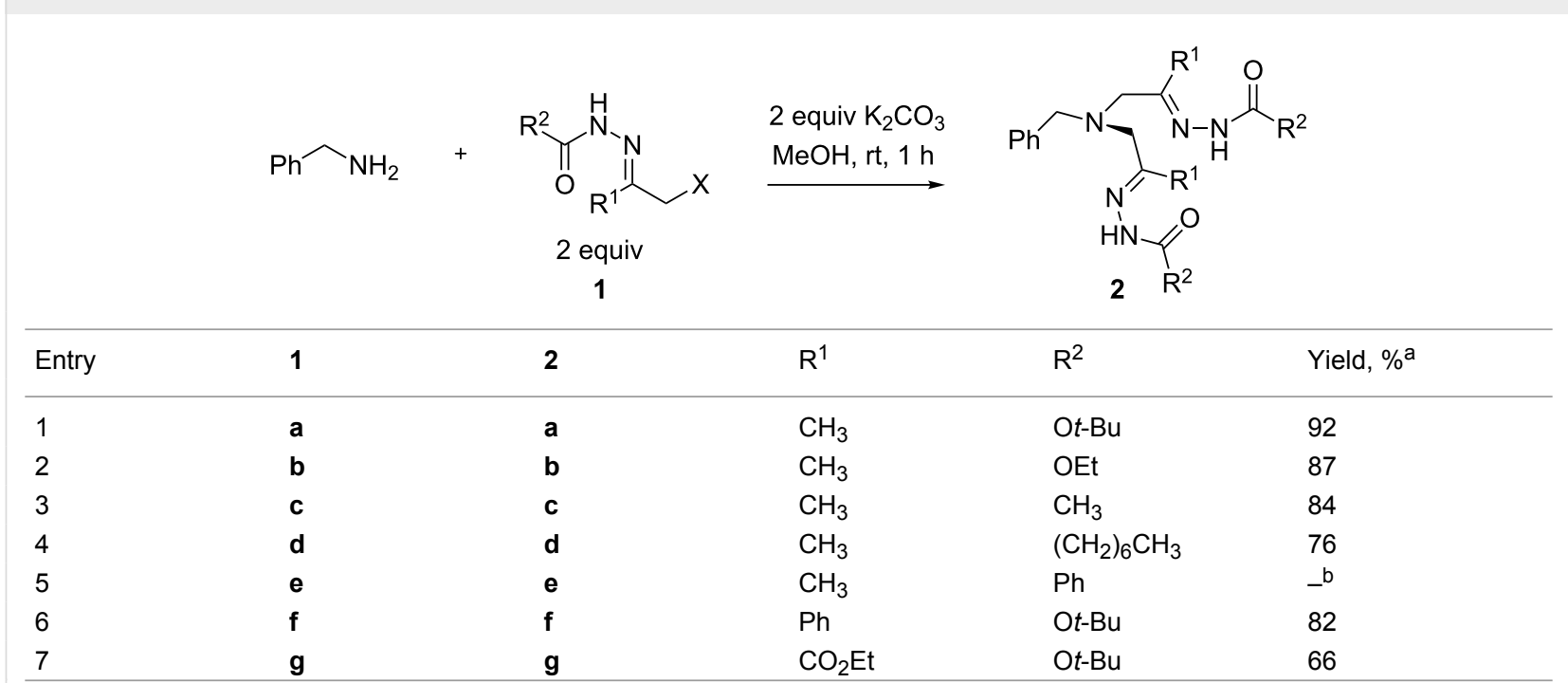

asolated yields. ${ }^{\mathrm{b} C o m p l e x}$ mixture of products. 
<smiles>C#CCN(C/C(C)=N/NC(=O)OCCCC)C/C(C)=N/NC(=O)OCCCC</smiles>

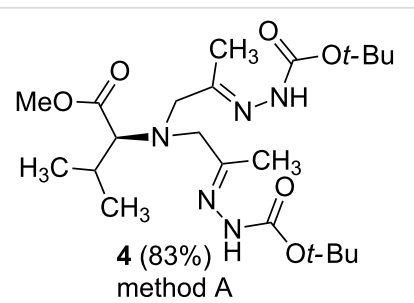

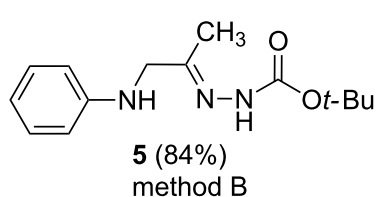<smiles>CCCCOC(=O)N/N=C(\C)CN1CCOCC1</smiles>

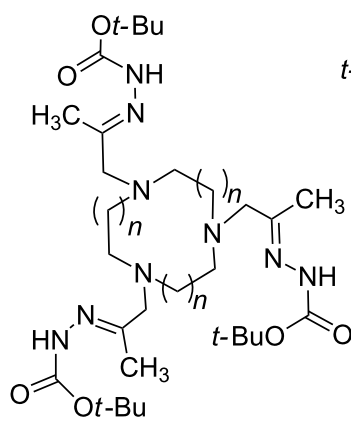

$7, n=1(82 \%)$ method $\mathrm{C}^{t-\mathrm{BuO}}$ $8, n=2(92 \%)$ method $C$

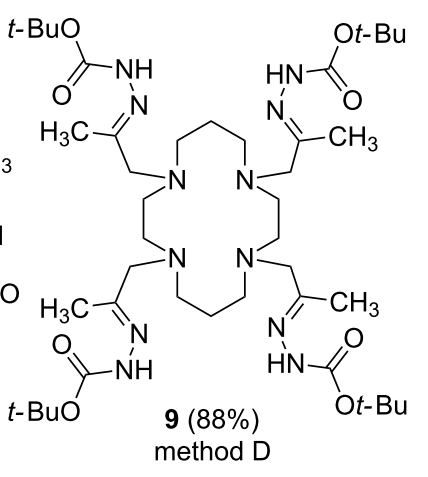

Figure 2: Structures of polyhydrazones 3-9. Methods: A: 1 equiv of amine, 2 equiv of $1 \mathrm{a}, 2$ equiv of $\mathrm{K}_{2} \mathrm{CO}_{3} ; \mathrm{B} ; 1$ equiv of amine, 1 equiv of 1a, 1 equiv of $\mathrm{K}_{2} \mathrm{CO}_{3} ; \mathrm{C} ; 1$ equiv of amine, 3.1 equiv of $1 \mathrm{a}, 3$ equiv of $\mathrm{K}_{2} \mathrm{CO}_{3} ; \mathrm{D}$. 1 equiv of amine, 4.2 equiv of $1 \mathrm{a}, 4$ equiv of $\mathrm{K}_{2} \mathrm{CO}_{3}$. Yield based on the amine used.

was used, a mixture of mono- and bisadducts was obtained. This may be attributed to the reduced nucleophility of the secondary amino group in the primarily formed adduct 5 . The reaction of aniline with 1.0 equiv of chlorohydrazone 1a gave 5 in $84 \%$ yield (method B in Figure 2). Similarly, the reaction with a secondary amine (morpholine) according to this procedure provided the monoalkylated adduct $\mathbf{6}$ in good yield.

Importantly, secondary polyamines could be exhaustively alkylated with chloroacetone hydrazone 1a demonstrating the effi- ciency of our approach for the synthesis of polyhydrazones. Thus, treatment of macrocyclic polyamines tacn (1,4,7-triazacyclononane), tacd (1,5,9-triazacyclododecane) and cyclam (1,4,8,11-tetraazacyclotetradecane) with 1a gave the corresponding tris- and tetra-hydrazones 7,8 and 9 , respectively, in high yields (methods C,D in Figure 2, a small excess of 1a was used to ensure complete alkylation). Macrocyclic polynitrogen ligands with several hydrazone arms may be of interest for the design of sensors [52] and contrast agents [53].

Unfortunately, alkylation of ethylenediamine with 4 equivalents of 1a led to an indecipherable mixture of products. In this case, the primary alkylation adducts might be unstable and undergo heterocyclization reactions (on the synthesis of heterocyclic compounds from azoalkenes and diamines see [5456]).

Bishydrazones containing clickable groups (like 3) can be introduced into functional molecules or immobilized on a support. This was demonstrated by the synthesis of a mixed triazolehydrazone ligand $\mathbf{1 0}$ by CuAAC reaction of $\mathbf{3}$ with phenyl azide (Scheme 3) (for application of mixed triazole-imine ligands see $[31,32,34])$.

\section{Reaction of $\alpha$-halogen-substituted hydra- zones 1 with ammonia}

Addition of $\alpha$-halohydrazones 1 to ammonia (Table 2) have a special significance because the expected trishydrazones $\mathbf{1 1}$ are obvious analogs of tris(iminomethyl)amines widely used in the catalysis of azide-alkyne cycloadditions [29-32,34]. Furthermore, intramolecular cyclotrimerization of $\mathrm{C}=\mathrm{N}$ bonds in trishydrozones would lead to unusual 1,4,6,10-tertraazaadamantane derivatives (vide infra) [57-60].

The treatment of model hydrazone 1a in $\mathrm{MeOH}$ with an excess of aqueous ammonia led to the desired trishydrazone 11a without the formation of corresponding primary and secondary amines or quaternary ammonium salts (Table 2, entry 1). Other hydrazones of $\alpha$-haloketones $\mathbf{1 b}, \mathbf{d}, \mathbf{f}$ and the hydrazone of chloroacetaldehyde $\mathbf{1 h}$ were successfully involved in the reac-<smiles>C#CCN(CC(C)=NC(=O)OCC)C/C(C)=N/NC(=O)OCCCC</smiles>

Scheme 3: Synthesis of a mixed triazole-hydrazone ligand 10 
Table 2: Synthesis of trishydrazones 11.<smiles>[X]CC([R])=NNC([R])=O</smiles>

\begin{tabular}{cccccc}
\hline Entry & $\mathbf{1}$ & $\mathbf{1 1}$ & $\mathrm{R}^{1}$ & $\mathrm{R}^{2}$ & \multicolumn{2}{c}{ Yield, \% } \\
\hline 1 & $\mathbf{a}$ & $\mathbf{a}$ & $\mathrm{CH}_{3}$ & $\mathrm{Ot}-\mathrm{Bu}$ & 83 \\
2 & $\mathbf{b}$ & $\mathbf{b}$ & $\mathrm{CH}_{3}$ & $\mathrm{OEt}$ & 46 \\
3 & $\mathbf{d}$ & $\mathbf{d}$ & $\mathrm{CH}_{3}$ & $\left(\mathrm{CH}_{2}\right)_{6} \mathrm{CH}_{3}$ & 73 \\
4 & $\mathbf{f}$ & $\mathbf{f}$ & $\mathrm{Ph}$ & $\mathrm{Ot}-\mathrm{Bu}$ & $65^{\mathrm{a}}$ \\
5 & $\mathbf{h}$ & $\mathbf{h}$ & $\mathrm{H}$ & $\mathrm{Ot}-\mathrm{Bu}$ & $66^{\mathrm{b}}$ \\
\hline
\end{tabular}

asecondary amine $\mathrm{HN}\left(\mathrm{CH}_{2} \mathrm{C}(=\mathrm{N}-\mathrm{NHBoc}) \mathrm{Ph}\right)_{2} 12 \mathrm{f}$ was also isolated in $24 \%$ yield. bYield on two steps from $\mathrm{BocNHNH}_{2}$.

tion with ammonia providing the corresponding trishydrazones $\mathbf{1 1 b}, \mathbf{d}, \mathbf{f}-\mathbf{h}$ in moderate to good yields (Table 2). In the case of phenyl-substituted hydrazone 1f, a bis-adduct $\mathbf{1 2 f}$ was obtained in addition to trishydrazone $\mathbf{1 1 f}$ (Table 2, entry 4).

\section{Cyclization of trishydrazones 11}

Upon treatment with acetic acid, trishydrazone 11b underwent a remarkable transformation to the tetraazaadamantane derivative 13b via intramolecular cyclotrimerization of $\mathrm{C}=\mathrm{N}$ bonds (Scheme 4). A similar reaction leading to $N$-hydroxy-substituted 1,4,6,10-tetraazadamantanes was recently observed by us for trisoximes [57-60]. However, 1,4,6,10-tetraazaadamantanes with three $\mathrm{N}$-amino groups are not accessible by the previously reported method from trisoximes [57-59]. Tetraazaadamantane with this substitution pattern is a promising platform for the design of supramolecular recognizing systems and for the construction of new molecular cage architectures.

The formation of the 1,4,6,10-tetraazaadamantane cage was unambiguously confirmed by X-ray analysis of the crystal solvate of 13b with water and methanol (Figure 3 ) as well as by ${ }^{1} \mathrm{H}$ and ${ }^{13} \mathrm{C}$ NMR spectra.

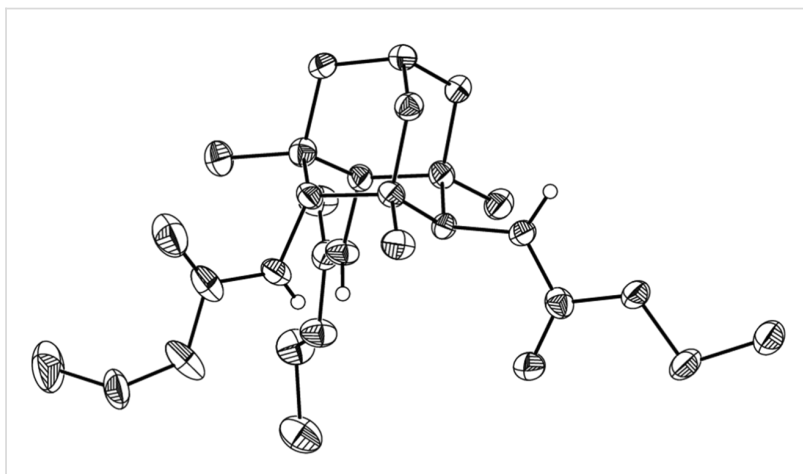

Figure 3: General view of 13b in representation of atoms with thermal ellipsoids at $50 \%$ probability level; all hydrogen atoms (except for those of the $\mathrm{NH}$ groups) are omitted for clarity. The compound crystallizes as a crystallosolvate with two water molecules and one methanol entity (those are not shown) per two symmetry-independent molecules of the product. CCDC 1501437 contains the supplementary crystallographic data for 13b. These data can be obtained free of charge via http:// www.ccdc.cam.ac.uk/conts/retrieving.html (or from the CCDC, 12 Union Road, Cambridge, CB21EZ, UK; or deposit@ccdc.cam.ac.uk).

Considering the reversible character of the imine cyclotrimerization [57,61], such a process may be viewed as a way to modulate the molecular geometry of trishydrazones bearing<smiles>CCOC(=O)N/N=C(\C)CN(C/C(C)=N/NC(=O)OCC)C/C(C)=N/NC(=O)OCC</smiles>

$\stackrel{\mathrm{AcOH}, \mathrm{rt}, 5 \mathrm{~min}}{\longrightarrow}$

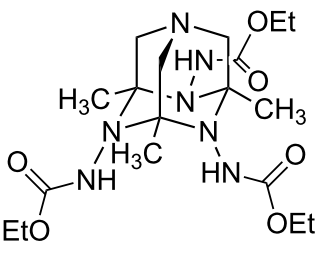

$13 b$

Scheme 4: Cyclisation of $11 \mathrm{~b}$ into 1,4,6,10-tetraazaadamantane derivative. 
functional fragments at nitrogen atoms. Further studies of this remarkable cyclization are ongoing.

\section{Structure and isomerism in hydrazones 2-12}

All newly obtained hydrazones were $\mathbf{2}-\mathbf{1 2}$ characterized by ${ }^{1} \mathrm{H}$, ${ }^{13} \mathrm{C}$ NMR spectroscopy and HRMS data. Most of the hydrazones were obtained as mixtures of $E / Z$-isomers (see Supporting Information File 1). The ratio of isomers depends on the substitution pattern and solvent. For example, the $E, E$-isomer was predominant for $\mathbf{2 a}$ in DMSO- $d_{6}$, while in $\mathrm{CDCl}_{3} E, Z-\mathbf{2 a}$ was the major isomer. The assignment of stereoisomers was performed using known correlations between the configuration of the $\mathrm{C}=\mathrm{N}$ bond and the chemical shift of hydrogen and carbon atoms attached to it [62].

\section{Conclusion}

In conclusion, we developed a convenient approach for the synthesis of hitherto unknown poly(hydrazonomethyl)amines I from $\alpha$-haloketones, hydrazides and simple amines (ammonia). Using this combinatorial approach, a series of new prospective bis-, tris- and tetrahydrazone ligands were prepared. Trishydrazone 11b was shown to undergo an intramolecular cyclotrimerization of the $\mathrm{C}=\mathrm{N}$ bonds resulting in the formation of the respective $N$-amino-substituted 1,4,6,10-tetraazaadamantane derivative. Further studies of coordination chemistry aspects of poly(hydrazonomethyl)amines I and their applications as ligands in transition metal catalysis are currently underway.

\section{Supporting Information}

\section{Supporting Information File 1}

Experimental procedures, characterization data for new compounds, copies of ${ }^{1} \mathrm{H}$ and ${ }^{13} \mathrm{C}$ NMR spectra. [http://www.beilstein-journals.org/bjoc/content/ supplementary/1860-5397-12-241-S1.pdf]

\section{Supporting Information File 2}

Crystal structure file for compound $\mathbf{1 3 b}$.

[http://www.beilstein-journals.org/bjoc/content/ supplementary/1860-5397-12-241-S2.cif]

\section{Acknowledgements}

This work was supported by the Russian Science Foundation (project 14-23-00150).

\section{References}

1. Su, X.; Aprahamian, I. Chem. Soc. Rev. 2014, 43, 1963-1981. doi:10.1039/c3cs60385g

2. Tatum, L. A.; Su, X.; Aprahamian, I. Acc. Chem. Res. 2014, 47, 2141-2149. doi:10.1021/ar500111f
3. Chandrasekhar, V.; Azhakar, R.; Bickley, J. F.; Steiner, A. Chem. Commun. 2005, 459-461. doi:10.1039/b414353a

4. Klein, J. M.; Saggiomo, V.; Reck, L.; McPartlin, M.; Dan Pantoş, G.; Lüning, U.; Sanders, J. K. M. Chem. Commun. 2011, 47, 3371-3373. doi:10.1039/c0cc04863a

5. Poolman, J. M.; Boekhoven, J.; Besselink, A.; Olive, A. G. L.; van Esch, J. H.; Eelkema, R. Nat. Protoc. 2014, 9, 977-988. doi:10.1038/nprot.2014.055

6. Stadler, A.-M.; Ramírez, J.; Lehn, J.-M.; Vincent, B. Chem. Sci. 2016, 7, 3689-3693. doi:10.1039/C5SC04403K

7. Buchs (née Levrand), B.; Fieber, W.; Vigouroux-Elie, F.; Sreenivasachary, N.; Lehn, J.-M.; Herrmann, A. Org. Biomol. Chem. 2011, 9, 2906-2916. doi:10.1039/С0ОВ01139H

8. Ratjen, L.; Lehn, J.-M. RSC Adv. 2014, 4, 50554-50557. doi:10.1039/C4RA11119B

9. Cao, X.-Y.; Harrowfield, J.; Nitschke, J.; Ramírez, J.; Stadler, A.-M.; Kyritsakas-Gruber, N.; Madalan, A.; Rissanen, K.; Russo, L.; Vaughan, G.; Lehn, J.-M. Eur. J. Inorg. Chem. 2007, 2944-2965. doi:10.1002/ejic.200700235

10. Chaur, M. N.; Collado, D.; Lehn, J.-M. Chem. - Eur. J. 2011, 17, 248-258. doi:10.1002/chem.201002308

11. Folmer-Andersen, J. F.; Lehn, J.-M. Angew. Chem., Int. Ed. 2009, 48, 7664-7667. doi:10.1002/anie.200902487

12. Folmer-Andersen, J. F.; Lehn, J.-M. J. Am. Chem. Soc. 2011, 133, 10966-10973. doi:10.1021/ja2035909

13. Pace, G.; Stefankiewicz, A.; Harrowfield, J.; Lehn, J.-M.; Samorì, P. ChemPhysChem 2009, 10, 699-705. doi:10.1002/cphc.200800733

14. Roy, N.; Buhler, E.; Lehn, J.-M. Polym. Int. 2014, 63, 1400-1405. doi:10.1002/pi.4646

15. Schaeffer, G.; Harrowfield, J. M.; Lehn, J.-M.; Hirsch, A. K. H. Polyhedron 2012, 41, 40-43. doi:10.1016/j.poly.2012.04.013

16. von Delius, M.; Geertsema, E. M.; Leigh, D. A. Nat. Chem. 2010, 2, 96-101. doi:10.1038/nchem.481

17. von Delius, M.; Geertsema, E. M.; Leigh, D. A.; Slawin, A. M. Z. Org. Biomol. Chem. 2010, 8, 4617-4624. doi:10.1039/c0ob00214c

18. Edison, S. E.; Hotz, R. P.; Baldwin, M. J. Chem. Commun. 2004, 1212-1213. doi:10.1039/b403668a

19. Goldcamp, M. J.; Robison, S. E.; Krause Bauer, J. A.; Baldwin, M. J. Inorg. Chem. 2002, 41, 2307-2309. doi:10.1021/ic015590w

20. Goldcamp, M. J.; Rosa, D. T.; Landers, N. A.; Mandel, S. M.; Krause Bauer, J. A.; Baldwin, M. J. Synthesis 2000, 2033-2038. doi:10.1055/s-2000-8724

21. Goldcamp, M. J.; Edison, S. E.; Squires, L. N.; Rosa, D. T.; Vowels, N. K.; Coker, N. L.; Krause Bauer, J. A.; Baldwin, M. J. Inorg. Chem. 2003, 42, 717-728. doi:10.1021/ic025860q

22. Semakin, A. N.; Sukhorukov, A. Yu.; Lesiv, A. V.; Khomutova, Y. A.; loffe, S. L.; Lyssenko, K. A. Synthesis 2007, 2862-2866. doi:10.1055/s-2007-983847

23. Semakin, A. N.; Sukhorukov, A. Yu.; loffe, S. L.; Tartakovsky, V. A. Synthesis 2011, 1403-1412. doi:10.1055/s-0030-1259995

24. Shalamova, E. A.; Lee, Y.; Chung, G.; Semakin, A. N.; Oh, J.; Sukhorukov, A. Yu.; Arkhipov, D. E.; loffe, S. L.; Semenov, S. E. Tetrahedron Lett. 2014, 55, 1222-1225. doi:10.1016/j.tetlet.2014.01.003

25. Dorokhov, V. S.; Jung, H.; Kang, G.; Andreev, Y. A.; Semakin, A. N.; Oh, J.; Sukhorukov, A. Yu.; loffe, S. L.; Semenov, S. E. Synth. Commun. 2015, 45, 1362-1366. doi:10.1080/00397911.2015.1021424 
26. Boyko, Y. D.; Sukhorukov, A. Yu.; Semakin, A. N.; Nelyubina, Y. V.; Ananyev, I. V.; Rangappa, K. S.; loffe, S. L. Polyhedron 2014, 71, 24-33. doi:10.1016/j.poly.2014.01.003

27. Premužić, D.; Muche, S.; Hołyńska, M. New J. Chem. 2014, 38, 2894-2901. doi:10.1039/C4NJ00194J

28. Premužić, D.; Korabik, M.; Hołyńska, M. J. Mol. Struct. 2014, 1059, 265-270. doi:10.1016/j.molstruc.2013.12.001

29. Chan, T. R.; Hilgraf, R.; Sharpless, K. B.; Fokin, V. V. Org. Lett. 2004, 6, 2853-2855. doi:10.1021/ol0493094

30. Rodionov, V. O.; Presolski, S.; Gardinier, S.; Lim, Y.-H.; Finn, M. G. J. Am. Chem. Soc. 2007, 129, 12696-12704. doi:10.1021/ja072678।

31. Presolski, S. I.; Hong, V.; Cho, S.-H.; Finn, M. G. J. Am. Chem. Soc. 2010, 132, 14570-14576. doi:10.1021/ja105743g

32. Lewis, W. G.; Magallon, F. G.; Fokin, V. V.; Finn, M. G. J. Am. Chem. Soc. 2004, 126, 9152-9153. doi:10.1021/ja048425z

33. Blackman, A. G. Polyhedron 2005, 24, 1-39. doi:10.1016/j.poly.2004.10.012

34. Semakin, A. N.; Agababyan, D. P.; Kim, S.; Lee, S.; Sukhorukov, A. Yu.; Fedina, K. G.; Oh, J.; loffe, S. L. Tetrahedron Lett. 2015, 56, 6335-6339. doi:10.1016/j.tetlet.2015.09.106

35. Attanasi, O. A.; Caglioti, L. Org. Prep. Proced. Int. 1986, 18, 299-327. doi:10.1080/00304948609356836

36. Attanasi, O. A.; Filippone, P. Synlett 1997, 1128-1140. doi:10.1055/s-1997-973

37. Attanasi, O. A.; De Crescenti, L.; Filippone, P.; Mantellini, F.; Santeusanio, S. ARKIVOC 2002, xi, 274-292.

38. Attanasi, O. A.; De Crescentini, L.; Favi, G.; Filippone, P.; Mantellini, F.; Perrulli, F. R.; Santeusanio, S. Eur. J. Org. Chem. 2009, 3109-3127. doi:10.1002/ejoc.200900243

39. Lemos, A. Molecules 2009, 14, 4098-4119. doi:10.3390/molecules 14104098

40. Beyer, H.; Badicke, G. Chem. Ber. 1960, 93, 826-833. doi:10.1002/cber.19600930411

41. Schultz, A. G.; Hagmann, W. K. J. Org. Chem. 1978, 43, 3391-3393. doi:10.1021/jo00411a029

42. Haelters, J. P.; Corbel, B.; Sturtz, G. Phosphorus, Sulfur Silicon Relat. Elem. 1988, 37, 65-85. doi:10.1080/03086648808074352

43. Arcadi, A.; Attanasi, O. A.; De Crescentini, L.; Rossi, E. Tetrahedron Lett. 1997, 38, 2329-2332. doi:10.1016/S0040-4039(97)00306-7

44. Palacios, F.; Aparicio, D.; López, Y.; de los Santos, J. M. Tetrahedron 2005, 61, 2815-2830. doi:10.1016/j.tet.2005.01.081

45. Yunoki, R.; Yajima, A.; Taniguchi, T.; Ishibashi, H. Tetrahedron Lett. 2013, 54, 4102-4105. doi:10.1016/j.tetlet.2013.05.110

46. Attanasi, O. A.; Berretta, S.; De Crescentini, L.; Favi, G.; Giorgi, G.; Mantellini, F. Adv. Synth. Catal. 2009, 351, 715-719. doi:10.1002/adsc.200800807

47. Attanasi, O. A.; De Crescentini, L.; Filippone, P.; Giorgi, G.; Nicolini, S.; Perrulli, F. R.; Santeusanio, S. Tetrahedron 2014, 70, 7336-7343. doi:10.1016/j.tet.2014.07.038

48. Attanasi, O.; Filippone, P.; Battistoni, P.; Fava, G. Synthesis 1984, 422-424. doi:10.1055/s-1984-30860

49. Perrulli, F. R.; Favi, G.; De Crescentini, L.; Attanasi, O. A.; Santeusanio, S.; Mantellini, F. Eur. J. Org. Chem. 2015, 7154-7159. doi:10.1002/ejoc.201501017

50. Kylmälä, T.; Hämäläinen, A.; Kuuloja, N.; Tois, J.; Franzén, R. Tetrahedron 2010, 66, 8854-8861. doi:10.1016/j.tet.2010.09.069
51. Attanasi, O. A.; De Crescentini, L.; Filippone, P.; Foresti, E.; Mantellini, F. J. Org. Chem. 2000, 65, 2820-2823. doi:10.1021/jo9917792

52. Tamanini, E.; Flavin, K.; Motevalli, M.; Piperno, S.; Gheber, L. A.; Todd, M. H.; Watkinson, M. Inorg. Chem. 2010, 49, 3789-3800. doi:10.1021/ic901939x

53. Caravan, P.; Ellison, J. J.; McMurry, T. J.; Lauffer, R. B. Chem. Rev. 1999, 99, 2293-2352. doi:10.1021/cr980440x

54. Aparicio, D.; Attanasi, O. A.; Filippone, P.; Ignacio, R.; Lillini, S.; Mantellini, F.; Palacios, F.; de los Santos, J. M. J. Org. Chem. 2006, 71, 5897-5905. doi:10.1021/jo060450v

55. Attanasi, O. A.; De Crescentini, L.; Favi, G.; Mantellini, F.; Nicolini, S. J. Org. Chem. 2011, 76, 8320-8328. doi:10.1021/jo201497r

56. Attanasi, O. A.; De Crescentini, L.; Favi, G.; Filippone, P.; Lillini, S.; Mantellini, F.; Santeusanio, S. Synlett 2005, 1474-1476. doi:10.1055/s-2005-868517

57. Semakin, A. N.; Sukhorukov, A. Yu.; Lesiv, A. V.; loffe, S. L.; Lyssenko, K. A.; Nelyubina, Y. V.; Tartakovsky, V. A. Org. Lett. 2009, 11, 4072-4075. doi:10.1021/ol9015157

58. Semakin, A. N.; Sukhorukov, A. Yu.; Nelyubina, Y. V.; loffe, S. L.; Tartakovsky, V. A. Synthesis 2012, 1095-1101. doi:10.1055/s-0031-1289735

59. Semakin, A. N.; Sukhorukov, A. Yu.; Nelyubina, Y. V.; Khomutova, Y. A.; loffe, S. L.; Tartakovsky, V. A. J. Org. Chem. 2014, 79, 6079-6086. doi:10.1021/jo5007703

60. Golovanov, I. S.; Sukhorukov, A. Yu.; Nelyubina, Y. V.; Khomutova, Y. A.; Ioffe, S. L.; Tartakovsky, V. A. J. Org. Chem. 2015, 80, 6728-6736. doi:10.1021/acs.joc.5b00892

61. García, J. M.; Jones, G. O.; Virwani, K.; McCloskey, B. D.; Boday, D. J.; ter Huurne, G. M.; Horn, H. W.; Coady, D. J.; Bintaleb, A. M.; Alabdulrahman, A. M. S.; Alsewailem, F.; Almegren, H. A. A.; Hedrick, J. L. Science 2014, 344, 732-735. doi:10.1126/science. 1251484

62. Palla, G.; Predieri, G.; Domiano, P.; Vignali, C.; Turner, W. Tetrahedron 1986, 42, 3649-3654. doi:10.1016/S0040-4020(01)87332-4

\section{License and Terms}

This is an Open Access article under the terms of the Creative Commons Attribution License (http://creativecommons.org/licenses/by/4.0), which permits unrestricted use, distribution, and reproduction in any medium, provided the original work is properly cited.

The license is subject to the Beilstein Journal of Organic Chemistry terms and conditions:

(http://www.beilstein-journals.org/bjoc)

The definitive version of this article is the electronic one which can be found at: $\underline{\text { doi:10.3762/bjoc. } 12.241}$ 